was enhanced by puncturing a few holes in the thicker region of the alimentary canal. The changes in colour of the gut in all the four species were carefully noted and their approximate $p H$ value determined by comparison with a Hellige standard colour disc for bromthymol blue. The ranges of variation of $p \mathrm{H}$ in each species are those of different regions of the gut and to some extent include the individual variations.

The accompanying table shows that the degree of variation in the $p \mathrm{H}$ of the alimentary canal is small, yet it is suggestive enough to indicate that the alimentary canal of the blood suckers is slightly more acidic than that of those which do not suck blood. The relation of the acidity of the gut with the development of flagellates inside it is being investi. gated and will be published elsewhere.

\begin{tabular}{|l|c|}
\hline $\begin{array}{c}\text { Phlebotomus papatasii, Scop., } \\
\text { (Mammalian blood sucker and } \\
\text { Leishmania tropica carrier) }\end{array}$ & $p$ H value \\
\hline $\begin{array}{c}\text { Phlebotomus argentipes, Ann. and Brun., } \\
\text { (Mammalian blood sucker and } \\
\text { Leishmania donovani carrier) }\end{array}$ & $\begin{array}{c}6 \cdot 2-6 \cdot 4 \\
\text { Stomach-Little or } \\
\text { no reaction }\end{array}$ \\
\hline \begin{tabular}{c} 
Phlebotomus minutus (sensu lato), Rond. \\
\hline $\begin{array}{c}\text { Psychoda alternata, Say sexpunctata, Curt. } \\
\text { (Non blood sucker) }\end{array}$
\end{tabular} & $6 \cdot 2-6 \cdot 4$ \\
\hline
\end{tabular}

Kala-azar Enquiry,

S. MukerJi.

All India Institute of Hygiene

and Public Health,

Calcutta.

Jan. 24.

\section{Simultaneous Travel of a Surge of Stress and a Group of High-Frequency Waves of Stress in a Steel Wire}

That a high frequency longitudinal vibration will travel more slowly than a low frequency one may be qualitatively foretold from Rayleigh's ${ }^{1}$ treatment of the effect of lateral inertia on the natural period of longitudinal vibration of cylindrical rods. However, when Rayleigh's formula is applied to the case given by $\mathrm{Dr}$. Wall ${ }^{2}$, where the wave-length is stated to be 18 inches and the diameter $0 \cdot 123$ in., the effect of lateral inertia is found to be negligible.

Rayleigh's formula has been experimentally in. vestigated by $R$. W. Boyle and myself ${ }^{3}$ and by Muzzey $^{4}$, and found to be applicable over a range of the ratio of wave-length to diameter including this case. It is suggested that the necessity of postulating a hitherto unknown effect may be avoided by assuming that the group of waves has a higher frequency than that given by Dr. Wall, determined possibly by the natural period of a clamp, this high frequency being 'modulated' at the inter-clamp frequency by successive reflections, and 'demodulated' in the amplifier, which the oscillograms show to have the necessary characteristics.

Dr. Wall's oscillograms show that the ratio of the two velocities is about $1: 1 \cdot 3$ and Poisson's ratio for iron may be taken as $\mathbf{0 \cdot 3}$ (Kaye and Laby). These values inserted in Rayleigh's formula give a ratio of diameter to wave-length of $1 \cdot 2$. The results of Boyle and myself show that Rayleigh's formula is not applicable when this ratio exceeds $0 \cdot 55$, probably due to the neglect of shear stresses, the approach to resonance of radial vibration, and viscosity. Field has given an analysis which includes these factors, and whether or not this analysis can be applied to explain the interesting results given by Dr. Wall, it is clear that Dr. Wall's method of measuring the velocity of longitudinal vibrations may be adapted to an experimental investigation of the factors included in Field's analysis.

3 Gower Street,

London, W.C.1.

1 "Theory of Sound", vol. 1, p. 251.

2 NATURE, 135, $151 ; 1935$.

3 Canad. J. Research, 5, 601; 1931

- Phys. Rev., 38, 935; 1930 .

${ }^{-}$Canad. $J$. Research, 11, 254; 1934.

D. O. Sproule.

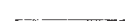

\section{Science and Social Progress}

MAY I suggest that the decline of the adventurous spirit is due not so much to standardisation and mechanisation, as might be gathered from the leading article in NATURE of February 16, p. 245, as to specialisation? A specialist, as I have said elsewhere, is "a human being who has narrowed the sphere of his activity at the expense of his social instincts, thereby becoming but a fraction of a man. $\mathrm{He}$ sees a field of activity as brightly lit, perhaps, but as limited as the field of a microscope; and not infrequently it is as though the microscope was a little out of focus. There is a blurring as of things too close to the eyes to be distinctly seen."

I am under no illusion that specialisation can be dispensed with altogether, but I am heterodox enough to believe that we should be more truly civilised if there were more jacks of all trades and fewer masters of one. How can any man who has only read, let us say, Chapter $x x$ of the 'book of life' hope to acquire that comprehensive vision of the human adventure in time and space, so essential to ensure sane social development?

Since mechanisation has been mentioned, I should like to take this opportunity to combat the belief, now being revived in various quarters, that machinery, after all, does not cause unemployment. It will be seen that the subject is not irrelevant. This particular fallacy was exposed 116 years ago by Jean Sismondi as follows: "Every new product must in the long run give rise to some fresh consumption. But let us desist from our habit of making abstraction of time and place. Let us take some account of the obstacles and the friction of the social mechanism. And what do we see? The immediate effect of machinery is to throw some of the workers out of employment. . . . A certain kind of equilibrium, it is true, is re-established in the long run, but it is only after a frightful amount of suffering."

In short, it is little consolation to a man thrown out of employment now, to know that 'in the long run' and 'on the average' scientific and technological development creates new opportunities. In the long run (as I think Mr. Keynes once remarked) we are all dead. Adjustment of the individual to mechanical progress, with less of both short run and long run unemployment, would be easier if men were less specialised, better equipped for turning readily from one type of employment to another.

20 Ridgeway Place,

Hugh P. Vowles. S.W.19. 